\title{
Social Coping and Self-Concept among Young Gifted Students in Ireland and the United States: A Cross-Cultural Study
}

Jennifer Riedl Cross

College of William and Mary, jrcross@wm.edu

Colm O'Reilly

Dublin City University

Mihyeon Kim

College of William and Mary, mxkim3@wm.edu

Sakhavat Mammadov

College of William and Mary, smammadov@email.wm.edu

Tracy L. Cross

College of William and Mary, tlcross@wm.edu

Follow this and additional works at: https://scholarworks.wm.edu/articles

Part of the Gifted Education Commons

\section{Recommended Citation}

Cross, Jennifer Riedl; O'Reilly, Colm; Kim, Mihyeon; Mammadov, Sakhavat; and Cross, Tracy L., "Social Coping and Self-Concept among Young Gifted Students in Ireland and the United States: A Cross-Cultural Study" (2015). Articles. 72.

https://scholarworks.wm.edu/articles/72

This Article is brought to you for free and open access by W\&M ScholarWorks. It has been accepted for inclusion in Articles by an authorized administrator of W\&M ScholarWorks. For more information, please contact scholarworks@wm.edu. 
Social Coping and Self-Concept Among Young Gifted Students in Ireland and the United

States: A Cross-Cultural Study

Jennifer Riedl Cross, Ph.D.

Center for Gifted Education

College of William and Mary

Colm O’Reilly, Ph.D.

Centre for Talented Youth, Ireland

Dublin City University

Mihyeon Kim, Ph.D.

Sakhavat Mammadov, MA

Tracy L. Cross, Ph.D.

Center for Gifted Education

College of William and Mary

Corresponding Author:

Jennifer Riedl Cross

jrcross@wm.edu

(757) 221-2414

Center for Gifted Education

College of William \& Mary

P. O. Box 8795

Williamsburg, VA 23187 


\begin{abstract}
Social coping and self-concept were explored among Irish $(n=115)$ and American $(n=134)$ grades $3-8$ students. Denying one's giftedness or the impact it has on peer relationships were associated with poor self-concept in both samples. Among Irish students, denying giftedness was associated with more positive self-concept when paired with a high activity level. Engaging in many activities in the US sample and helping one's peers in the Irish sample were positive predictors of academic self-concept. Findings suggest young gifted students may benefit from learning more about their exceptional abilities and their impact on peers. They should also be encouraged to engage in extracurricular activities and find ways to use their exceptional abilities to support their peers.
\end{abstract}

Keywords: young gifted, social coping, stigma, self-concept 


\section{Social Coping and Self-Concept Among Young Gifted Students in Ireland and the United States: A Cross-Cultural Study}

Students with gifts and talents have different experiences in school and life from the average student (Coleman, 2012), because of their exceptional abilities. They are able to move faster through the curriculum in the area of their talents (Reis, et al., 1993), meaning that they are often waiting while others are continuing to learn (Peine \& Coleman, 2010). They will often find academic tasks easier than their peers, meaning that they will be recognized by their peers for superior performance at a rate much higher than average (Exline \& Lobel, 1999). Many consider themselves to be more serious about learning than their peers (Cross, Coleman \& Stewart, 1993), meaning that they may be occupied with learning activities while their peers are engaged in other activities. As social creatures, all of us have a need to belong, to find peers who accept us and with whom we feel related (Baumeister \& Leary, 1995; Deci \& Ryan, 1985; Maslow, 1987). Being or feeling different can inhibit the relationships one can build, either by uncertainty on the part of the individual or by rejection of others. In their differentness, students with gifts and talents face challenges to relationship-building that are unique to them and associated with their exceptional abilities. As students with gifts and talents approach the social tasks appropriate for their age mates, they may need support from adults who understand their unique situation and can guide them. An understanding of their social experiences can lead to structuring the environment in ways that facilitate relationship-building, rather than interfering with it.

Building on the research developed from Coleman's (1985) Stigma of Giftedness Paradigm, this study examines students' social coping and the relationship of coping to selfconcept. To better understand the universality of the social experience of students with gifts and talents, these constructs are explored in the US and in Ireland, which has a very different history 
of providing services to students with gifts and talents (O'Reilly, 2013). The following research questions guided the study:

1) Is there a relationship between self-reported social coping behaviors and self-concept?

2) Are there differences in social coping, self-concept, or the relationship between the two among U.S. and Irish students?

\section{Background of the Study}

\section{Self-Concept Among Gifted Students}

Self-concept, the perception each of us has about the self, has been the subject of much study since William James (1963/1890) wrote about “The Consciousness of Self” in his Principles of Psychology. The nuances of this self-concept have become more clear, as research has moved from a unidimensional construct (e.g., Rosenberg, 1979) towards a multidimensional, hierarchical model, with a global self-concept overarching academic, social, emotional, and physical self-concepts (Shavelson, Hubner, \& Stanton,1976). According to Marsh and Shavelson (1985), more global self-concepts, those higher up the hierarchy, tend to be more consistent, with little situational variability. As self-concepts become more differentiated, between math and verbal academic self-concepts, for example, there is greater variability associated with different situations.

Self-concepts develop through social understanding, from one's interpretations of personal experiences and reflected appraisals (Rayner, 2001). There is a developmental progression of self-concept, with greater distinctions developing between specific dimensions of the self with maturity (Marsh \& Shavelson, 1985). The shift from elementary to middle school is accompanied by a major transition in academic self-concept as cognition and environment undergo dramatic changes (Eccles, Midgley, \& Adler, 1984). Marsh, Trautwein, Lüdtke, Köller, 
and Baumer (2006) use the terms self-esteem and global self-concept interchangeably, considering the evaluative dimension of responses to general questions about the self (e.g., In general, I like being the way I am.) to be indistinguishable from a descriptive dimension.

The relationship of self-concept consistency and well-being has been empirically supported over the years (McReynolds, Altrocchi, \& House, 2000), the consistency hypothesis (Locke, 2006). Equally important to consistency, however, appears to be the content of one's self-concept. Locke (2006) identified desirability of traits as more strongly related to measures of well-being than a general between-situation correlation coefficient. A positive self-concept, particularly in the domain of achievement, is highly correlated with academic success in that domain, whereas self-esteem is unrelated (Marsh, 1990, 1993). Self-concept has been associated with happiness (Holder \& Coleman, 2008; O'Rourke, Cooper, \& Gray, 2012) and with academic achievement (Marsh, Byrne, \& Shavelson, 1988; Marsh \& Yeung, 1997a; Skaalvik \& Skaalvik, 2009). Beliefs about one's academic abilities are predictive of academic achievement in those domains (Marsh et al., 2006; Marsh \& Yeung, 1997a; Möller, Pohlmann, Koller, \& Marsh, 2009; Skaalvik \& Skaalvik, 2009) and there is evidence of a reciprocal effect of self-concept and achievement (Skaalvik \& Hagtvet, 1990). Marsh and Yeung (1997b) found that a positive selfconcept in different subject areas was related to the desire to take coursework in that subject. In contrast, global and non-academic self-concepts are unrelated to subsequent academic achievement (Marsh, 1993).

It stands to reason that gifted or above average students have more positive academic self-concepts than their average peers. In their comparison of U.S. gifted students in grades 6-10 with the normative sample of primarily Australian students of grades 7-11, Marsh, Plucker and Stocking (2001) found the gifted sample scored on average more than a full standard deviation 
higher than the norm group on the academic subscales. In their meta-analysis of 15 studies comparing self-concept of gifted and nongifted samples, Hoge and Renzulli (1993) found the gifted samples had more positive academic self-concept (effect size $=.47$ ), but similar nonacademic (social and physical) self-concepts. Global self-concept scores were slightly higher in the gifted sample (ES=.19). The reciprocal effect of positive academic self-concept and achievement (Marsh \& Yeung, 1997a; Skaalvik \& Hagtvet, 1990), combined with the choices of coursework associated with positive self-concept (Marsh \&Yeung, 1997b) can create an upward spiral of success. Gifted students who feel positively about their abilities subsequently achieve and go on to choose courses and perform successfully in the subject areas they believe they are good in. A positive academic self-concept is important to academic success.

\section{Social Coping}

The critical role of social experiences in the construction of one's self-concept (Rayner, 2001) suggests that an understanding of one is necessary for an understanding of the other. Research indicates that some gifted students experience difficulties in the social domain (Kerr, Colangelo, \& Gaeth, 1988; Manor-Bullock, Look, \& Dixon, 1995), and feel they are different from age-peers (Coleman \& Cross, 1988; Cross, Coleman \& Stewart, 1993; Manor-Bullock et al., 1995). One factor that may influence gifted children's social relations is the presence of stigma. According to Cross, Coleman and Stewart (1993), the stigma accompanying a gifted label may result in gifted adolescents experiencing a feeling of "differentness" from their peers. The belief in a stigma towards being gifted can have a damaging effect in social relationships of gifted children. In their stigma of giftedness paradigm, Coleman and Cross (1988) proposed that normal social interaction will be distorted if a gifted individual believes the stigma is present, even if its presence is not proven. 
Some gifted students believe that others perceive them as stereotypically different because of their giftedness (Manor-Bullock et al., 1995). Kerr and colleagues (1988) found that giftedness, while viewed positively in terms of personal and academic development, is a disadvantage in social relationships. Gifted students often act to reduce the effects of stigma (Coleman, 1985; Coleman \& Cross, 1988; Coleman \& Sanders, 1993; Cross \& Swiatek, 2009; Huryn, 1986; Manor-Bullock et al., 1995). They may try to hide their giftedness and engage in camouflaging behaviors and thoughts in order to increase their latitude in developing social relationships (Coleman \& Cross, 1988; Cross, Coleman, \& Terhaar-Yonkers, 1991; Gross, 1989; Tannenbaum, 1983).

Research has suggested specific strategies that gifted students employ to avoid the recognition of their exceptional abilities. Some gifted students would prefer to underachieve and be popular than to be socially excluded after achieving honor status (Tannenbaum, 1983). Some students use less sophisticated vocabularies when among age-peers than when among trusted individuals (Gross, 1989), manage the information about themselves they make available to others (Coleman, 1985; Coleman \& Cross, 1988), varying their behavior in response to the degree to which they perceive the situation to be stigmatizing (Cross, Coleman, \& TerhaarYonkers, 1991). Swiatek (1995) sought quantitative support for these identified coping strategies, developing the Social Coping Questionnaire (SCQ) to explore strategies that gifted students employ in dealing with their giftedness in social situations. Different versions of the SCQ have included items reflecting such strategies as denial of one's giftedness, using humor, engaging in many extracurricular activities, denying the impact of giftedness on one's acceptance by peers, conformity, helping others, and emphasizing the unimportance of one's popularity. 
From studies using the SCQ, it is evident that gifted students engage in behaviors or adopt beliefs related to their social experiences. Behaviors such as involvement in extracurricular activities, using humor in social situations, helping peers, or conforming are active means of engaging with peers. The beliefs some gifted students adopt are a result of one's social cognition. Believing that one is not gifted, that one's giftedness has no impact on social relations (Peer Acceptance), or that one's popularity is unimportant may not be strategies for dealing with the stigma of giftedness as much as they are a mindset about one's abilities or perceptions of the significance of differentness. Lazarus and Folkman (1984) describe two types of coping in response to stress: emotion-focused (managing emotional responses to stress) and problemfocused (changing the stressful situation). The beliefs identified by the SCQ may be emotionfocused coping strategies or they may be representations of the gifted student's perceptions and values. The SCQ treats these beliefs as strategies, assuming they are a means of coping socially.

Studies associating Swiatek's $(1995,2001)$ coping strategies with measures of well-being indicate that some strategies may be more positive than others. Engaging in many activities and helping others are two strategies that have been associated with positive self-concept or other indicators of well-being in multiple studies (e.g., Chan, 2003; Swiatek, 2001). Denying giftedness, a strategy used more frequently by females than males (Swiatek, 2001; Swiatek \& Cross, 2007; Swiatek \& Dorr, 1998), has been associated with lower self-concept (Swiatek, 2001) and unhealthy ideation (Chan, 2004). Swiatek and colleagues (Swiatek, 2001; Swiatek \& Cross, 2007) found greater use of humor among males than females. Swiatek (2001) found a negative relationship between denying the influence of giftedness on peer acceptance and selfconcept (particularly of peer relationships), but Chan $(2003,2004)$ found it to be positively related to emotional intelligence and other indicators of well-being in a Chinese sample. Younger 
gifted students are less likely to consider popularity important than older students (Chan, 2004, 2005; Foust, Rudasill, \& Callahan, 2006; Swiatek, 2002). Older students may be more likely to help others than their younger peers (Chan, 2005; Foust et al., 2006; Swiatek, 2001).

Social coping among gifted students and self-concept are intricately linked, as numerous studies have found (Swiatek, 1995, 2001;Swiatek \& Cross, 2007; Tomchin \& Callahan, 1996). Although a few studies have explored these questions with non-U.S. samples (e.g., Chan, 2004, 2005), little is known about how the relationship of social coping and self-concept differs between gifted students in and outside the US. In this study, we will explore the relationship of these constructs in a cross-cultural sample of young Irish and U.S. gifted students.

\section{Method}

\section{Participants}

Participants in the U.S. sample were 134 students in Grades 3-8 who were taking part in a week-long summer enrichment program. To be eligible for the program, students were required to perform at the $95^{\text {th }}$ percentile on any subscale of a standardized ability, achievement, or creativity test. Males made up 61\% (n=80) of the sample; females 39\% (n=51). Three students did not report their gender. Elementary students made up 50\% $(n=66)$ of the sample; secondary $50 \%(n=67)$.

For the Irish sample, third to eighth grade students $(N=115)$ in a summer enrichment program in Ireland participated in this study. Irish students also had to score at the $95^{\text {th }}$ percentile in a standardized achievement test in the areas of either mathematical, verbal or abstract reasoning to be eligible for the program. Fifty-five percent $(n=63)$ of the sample was male and $40 \%$ female $(n=46)$. Six students did not report their gender. The majority of students were secondary $(67 \% ; n=77)$ and $33 \%(n=38)$ were elementary. 


\section{Instruments}

The Self-Description Questionnaire-I (SDQ-I; Marsh, 1992) is a 76-item survey with three dimensions represented by eight subscales: Academic Self-Concept (General School, Reading, Math); Non-Academic Self-Concept (Physical Appearance, Physical Ability, Parent Relations, Peer Relations); General Self-Concept. The SDQ-I is designed for children from ages 8-12.

Swiatek’s (2001) Social Coping Questionnaire (SCQ) is a 34-item survey with seven subscales, each representing a coping strategy: Denying Giftedness (e.g., People think that I am gifted, but they are mistaken), Using Humor (e.g., I tell a lot of jokes in school), Activity Level (e.g., I spend quite a bit of time on extracurricular activities), Peer Acceptance (e.g., I would fit in better at school if I were not gifted), Conformity (e.g., I try to act very much like other students act), Helping Others (e.g., People come to me for help with their homework), and Focus on Popularity (e.g., I don't worry about whether or not I am popular). Reliability of these subscales varies across studies, with Cronbach's alpha levels from just above .5 to above .8 (see Rudasill et al., 2007, Table 1, for a summary of reliabilities).

The SCQ has undergone substantial revisions as it has been tested in various samples (e.g., Chan, 2003; Cross \& Swiatek, 2009; Swiatek \& Cross, 2007; Swiatek \& Dorr, 1998). From the original instrument with four social coping strategies (Denial of Giftedness, Popularity/Conformity, Peer Acceptance, and Activity Level), Swiatek's (2001) version expanded to include seven strategies (Denying Giftedness, Using Humor, Activity Level, Peer Acceptance, Conformity, Helping Others, and Focus on Popularity). Factor analyses in various studies have resulted in different combinations of items that indicate potentially different strategies. For example, items pertaining to hiding were generally included as part of other 
strategies (Chan, 2004, 2005; Rudasill, Foust, \& Callahan, 2007; Swiatek, 1995, 2001, 2002;

Swiatek \& Cross, 2007), but in two studies hiding emerged as a separate strategy (Rudasill et al., 2007; Swiatek \& Dorr, 1998). Once items representing a humor strategy were added into the SCQ, some studies found it as a separate strategy (Swiatek, 2001, 2002; Swiatek \& Cross, 2007), whereas some did not (Rudasill et al., 2007). A helping strategy was sometimes found as a separate strategy (Chan, 2005; Rudasill et al., 2007; Swiatek, 2001) and sometimes items pertaining to it emerged as a part of other strategies (Swiatek, 2002; Swiatek \& Cross, 2007; Swiatek \& Dorr, 1998). While other means of measuring social coping have been developed (e.g., Adolescent Coping Scale; Frydenberg \& Lewis, 1991), only the SCQ was designed specifically to test social coping among gifted students, taking into account research on the experiences of gifted students.

To reflect the different terminology in U.S. and Irish culture, the term gifted was replaced with high academic ability in the Irish survey. One item - I don't think that I am gifted - was included in the Irish survey, along with the alternate version - I don't think that I have high academic abilities. These items were correlated at $r=.63, p<.001$.

\section{Procedure}

Students in summer enrichment classes who were given parental permission to participate received a packet of surveys (paper-and-pencil) during 30 minutes of one class period at the end of the program. Demographics, including gender, age and grade were collected. Three instruments were included in the packet, but only the SDQ-I (Marsh, 1992) and the SCQ (Swiatek, 2001) are analyzed in this study. An attempt was initially made to combine the two datasets, but preliminary analyses indicated that the structure of the data in each was significantly different. Rather than forcing the data into a single analysis, the decision was made 
to analyze Irish and U.S. datasets separately, following the same procedures. Except when otherwise specified, analyses were conducted with SPSS 22 for PC.

Descriptive analyses included multiple analysis of variance to identify self-concept differences between the Irish and U.S. samples. Based on the different factor structures found in previous studies, exploratory factor analysis of the SCQ items was executed with each sample. The coping factors were utilized in a multiple regression for prediction of self-concept. To further explore relationships of coping behaviors with self-concept at the individual level, cluster analysis was executed on the self-concept subscales.

\section{Results}

\section{Self-Concept}

The Self-Description Questionnaire I (SDQ-I; Marsh, 1992) was used to examine U.S. and Irish high ability students' self-concept. In the U.S. sample, Cronbach's alpha coefficients for the eight SDQ-I subscales ranged from .74 to .90, with a median reliability of .82 (see Table 3). In the Irish sample, Cronbach's alpha coefficients were acceptable, with a median reliability of .77. All components of self-concept were higher in the U.S. sample than the Irish sample $\left(\right.$ Pillai's Trace $=.39, F(8,240)=1479.33, p<.001, \eta_{p}{ }^{2}=.39$; see Table 3$)$.

\section{Social Coping}

Reliability analysis for the original seven social coping subscales in both samples yielded very low Cronbach's alphas, from .43 to .82 in Irish and from .38 to .67 in U.S. samples. Rather than continue the analysis with factors having poor reliability, Exploratory Factor Analysis (EFA) using Principal Axis Factoring extraction and Promax rotation was conducted to identify potentially more reliable factors. Multiple criteria were used to determine the number of factors to retain. The initial criterion of a minimum eigenvalue of 1.0 resulted in 12 factors in both 
samples. However, some of the factors had only one item and some were difficult to interpret. Both parallel analyses, conducted with Stata version 12.1 for Mac, and an examination of scree plots with Irish and U.S. datasets indicated that seven factor solutions in both samples were interpretable as psychologically meaningful social coping factors. Items with loadings below .30 were dropped from the analysis. These included I try to hide my gifts from other students, I try to get involved in sports so that people don't think of me as a 'geek', Most people see me as quite serious, and I spend part of my study time in group-study sessions for the U.S. sample and It doesn't matter what other people think about me, If I did not have high academic abilities, other kids in my school would not like me any more or less than they do now, I don't like to give the appearance of being studious, I spend part of my study time in group-study sessions, and I keep myself quite busy most of the time for the Irish sample.

The factors in the U.S. sample were Conformity $(\alpha=.61)$, Humor $(\alpha=.78)$, Deny Giftedness ( $\alpha=.66)$, Activity $(\alpha=.70)$, Deny Impact ( $\alpha=.70)$, Unconcerned $(\alpha=.53)$, and Hiding $(\alpha=.48)$. The factors in the Irish sample were Deny Giftedness $(\alpha=.80)$, Humor $(\alpha=.68)$, Appearance $(\alpha=$ $.57)$, Unconcerned $(\alpha=.65)$, Helping ( $\alpha=.54)$, Deny Impact $(\alpha=.61)$, and Conformity $(\alpha=.71)$. These are not strong reliability scores, but they are an improvement over Swiatek's (2001) subscale reliabilities with these samples. Tables 1 and 2 describe social coping factor loadings in U.S. and Irish samples. Some factors in the two samples were composed of different items, but had conceptually similar qualities. Conceptual differences can be seen in the U.S. Hiding and the Irish Appearance factors, which, in the U.S. sample includes only two items (I don't tell people that I am gifted and I try not to tell people my test grades), but in the Irish sample includes these items along with two items about being involved in extracurricular activities (I spend quite a bit of my time on extracurricular activities and I find friends who have interests similar to mine by 
getting involved in extracurricular activities). These factors are interpreted as managing appearances, which the Irish students seem to do through both hiding behaviors and engagement in extracurricular activities.

Another structural difference results in the emergence of an Activity factor in the U.S. sample, but not in the Irish sample. Instead, the Activity factor, which in the U.S. sample includes helping behaviors along with extracurricular involvement, is not present in the Irish sample. Helping items appear in a factor of their own in the Irish sample. Appearance, Hiding, Activity, and Helping factors mean different things in the two samples, but the other factors have similar meanings.

Predicting Self-Concept. Although studies have been conducted to test the relationship of social coping and self-concept (e.g., Swiatek, 2001; Tomchin \& Callahan, 1996), differences in instruments and methodology do not provide a strong theoretical foundation to recommend coping factors that will predict self-concept. For this reason, linear multiple regression analyses using the Enter method were performed to identify a model predicting students' academic selfconcept, non-academic self-concept, and general self-concept. All social coping factors, gender and age were entered into the regression for prediction of each self-concept subscale. Several of the variables contributed significantly to the prediction of academic, non-academic, and general self-concepts (see Table 4).

Cluster analysis. Taking a person-centered perspective on the data, hierarchical cluster analysis was performed to identify patterns of social coping by self-concept. Ward's Method was used to cluster individuals based on their academic, non-academic, and general self-concepts. Dendrograms indicated 3 clusters in both the U.S. and Irish samples: High, Medium, and Low self-concepts (see Tables 5 and 6 for demographics and mean scores by cluster). The U.S. 
elementary and secondary students are spread fairly evenly throughout the clusters, but there is a greater proportion of Irish secondary students in the Medium and Low self-concept clusters. The most notable pattern in both samples is the relationship between low self-concept and denying either one's giftedness/high abilities or their impact. The highest self-concept groups in both samples have the highest Activity (US) or Helping (Irish) scores. The predictive nature of social coping factors found through multiple regression is visible by cluster in Figures 1 and 2, which include only those social coping factors found to be significantly different $(p<.05)$ between clusters.

In the U.S. sample, three social coping strategies were found to be different among the three self-concept clusters with univariate analysis of variance and Tukey's correction for posthoc analysis. These strategies were Deny Giftedness $(F(2,131)=8.89, p<.05)$, Activity $(F(2$, $131)=9.51, p<.05)$, and Deny $\operatorname{Impact}(F(2,131)=3.42, p<.05)$. The low self-concept group is significantly higher in Deny Giftedness than both other groups. In Figure 1 it is evident that the gifted children who have the lowest self-concept are more likely to deny their giftedness. The high self-concept group is significantly higher in Activity than the medium and low selfconcept groups. The group with highest self-concept is most likely to employ the Activity strategies. The only significant difference in the Deny Impact factor occurs between the high and low self-concept groups. The group with the lowest self-concept is more likely to deny the impact of their giftedness than the highest self-concept group.

In the Irish sample, six social coping strategies were found to have significant differences among clusters. Only the Unconcerned strategy was not significantly different among the three self-concept groups, $F(2,112)=3.09, p=.05$. The highest self-concept group was significantly lower in Deny Giftedness than the lowest self-concept group, $F(2,112)=6.04, p<.05$. The 
group with the lowest self-concept is more likely to deny giftedness than the group with the highest self-concept. The highest self-concept group has the lowest Deny Impact level, which significantly differs from the other two, $F(2,112)=7.69, p<.05$. Conformity was lower among the highest self-concept group than the medium group, $F(2,112)=9.79, p<.01$, but was similar between the highest and lowest groups. The highest self-concept group employs Humor and Helping strategies frequently. This group significantly differs from the medium and lowest selfconcept groups in the use of Humor $F(2,112)=7.95, p<.05$, whereas a significant difference is found only between the highest and lowest self-concept groups for the Helping strategy, $F$ (2, $112)=4.16, p<.05$. Managing appearances through hiding and activities was lowest among the low self-concept students, $F(2,112)=5.28, p<.01$, but similar among high and medium.

\section{Discussion}

This study was guided by two research questions:

1. Is there a relationship between self-reported social coping behaviors and selfconcept?

2. Are there differences in social coping, self-concept, or the relationship between the two among U.S. and Irish students?

To answer these questions, data from two samples were analyzed to determine the structure of social coping, the contribution of social coping factors to the prediction of self-concept, and the patterns of social coping factors related to self-concept. The factor structure differed somewhat between the cross-cultural samples, but both had factors representing behavioral strategies (Humor, Activity/Helping, Conformity, Appearance/Hiding) and beliefs/values (Deny Giftedness, Deny Impact, Unconcerned). The relationship between social coping factors and selfconcept were evident in the comparison of coping factors among the High, Medium, and Low self-concept clusters. In both samples, beliefs that deny giftedness or its impact on peer 
acceptance were associated with a low self-concept. The behavioral Activity (US) and Helping (Irish) factors were most strongly associated with a high self-concept. Recall that the U.S. Activity factor includes helping items. In the Irish sample, there are also differences among clusters in the behavioral coping factors of Humor, Conformity, and Appearance, with greater use of these strategies associated with more positive self-concept. These patterns are reinforced by the multiple regression results. Activity and Helping are the most potent positive predictors of academic self-concept in both samples. The U.S. Activity and Irish Appearance factors, which share items related to extracurricular activities, are positive predictors of non-academic and general self-concept, as well. Being active, especially with peers, appears to contribute to a positive self-concept. In the Irish sample, negative beliefs (denial of abilities or their impact) are paired with activities from the Appearance factor in the Medium self-concept cluster. The Irish Low self-concept cluster also has the lowest Appearance scores. This suggests that engaging in extracurricular activities is somewhat protective of self-concept, even in the presence of negative beliefs. These findings support that of Swiatek (2001) and Chan (2003), who found that activities and helping were associated with positive self-concept and well-being. Denial of giftedness or its influence have been found to have negative implications in other studies (e.g., Chan, 2004; Swiatek, 2001; Swiatek \& Cross, 2007; Swiatek \& Dorr, 1998), but this study is unique in identifying a relationship between activities, including helping, and denial factors, as evidenced by the patterns of coping behaviors among the clusters.

In both the U.S. and Irish samples, denying one's giftedness or the impact of giftedness on peer acceptance is negatively associated with non-academic self-concept. As one is more likely to deny her or his abilities or their impact, beliefs about peer or parent relationships, physical appearance or abilities are more negative. No causal relationship can be identified through this 
analysis, but these findings suggest a complex of negative self-beliefs and poor relationships with others associated with a rejection or misinterpretation of one's academic abilities and their influence on peer acceptance. Being unconcerned about popularity, another belief identified with the SCQ, does not contribute to the prediction of self-concept, nor does it differ among the selfconcept clusters in either sample. The denial beliefs appear to be more significant to self-concept than a concern for popularity.

\section{Cross-Cultural Social Coping Differences}

Although we cannot compare social coping in the two datasets directly because of the differences in factor structure, the scores in the denial factors are noticeably smaller among the clusters in the U.S. sample (Deny Giftedness means of 1.92-2.72; Deny Impact means of 1.241.57; see Table 6) than in the Irish sample (Deny Giftedness means of 2.3-3.31; Deny Impact means of 2.19-3.27; see Table 6). A lower Deny Giftedness or Deny Impact score in the U.S. sample than in the Irish sample is associated with low self-concept. This difference may be the result of the terminology use in the surveys. U.S. students were responding to items such as $I \mathrm{am}$ not gifted; I am just lucky in school, and Being gifted does not hurt my popularity, whereas the Irish students were responding to the items I don't have high academic abilities; I am just lucky in school, and Having high academic abilities does not hurt my popularity. Low scores (U.S. sample) indicate a greater acceptance of the label gifted, whereas high scores (Irish sample) indicate a greater rejection of "high academic abilities."

Both Irish and U.S. students in the low self-concept cluster exhibited a relationship between self-concept and the denial of an impact of giftedness or high ability on peer acceptance. This denial was a negative predictor of academic self-concept in the U.S. sample, but not in the Irish sample. Whereas U.S. students' academic self-concept was less positive if they believed 
their giftedness does not matter to their popularity, this relationship was only evident among the Irish students in the low self-concept cluster. Here, again, terminology may make the difference. Does "being gifted" matter more to peer acceptance than "having high academic abilities"? If so, this may explain the resulting relationship with one's academic self-concept.

It is possible that the students in the U.S. sample have incorporated the gifted label into their identity. This label implies high academic abilities, but also often special services in school and a public distinction from peers. The history of the gifted label in U.S. schools extends beyond these children's parents' own elementary education. In Ireland, however, the gifted label has not been applied. It is unclear whether there is a stigma associated with giftedness in Ireland, but there has been evidence of such a stigma in the US (Coleman \& Cross, 2005). The interpretation of one's giftedness versus one's high academic abilities may result from different identity-related processes in two countries, one with an entity-focused label (gifted) and one with an emphasis on behaviors (academic performance).

The differences in SCQ factor structure are found primarily in the behavioral coping factors associated with activities. For example, the item I spend quite a bit of time on extracurricular activities loads on the Activity factor in the U.S. sample, but on the Appearance factor in the Irish sample. The item Because of all my activities, I don't have time to worry about my popularity falls under the Activity factor in the U.S. sample, but the Unconcerned factor in the Irish sample. Helping items load on the U.S. Activity factor, suggesting these students help others in the same way they engage in other activities, whereas in the Irish sample, helping items load on their own factor. These and other differences associated with active engagement with peers may signify a different role of activities in the two cultures. Extracurricular activities are generally associated with school in the US. Schools have their own sports teams, even at the 
elementary level. Band or orchestra are often offered during the school day, but may include after-school events. After-school clubs play an important role in middle school students' social and academic experience. In Ireland most of the extracurricular activities are not organized by the school. Students would likely join local sport clubs or receive specialized music tuition in a separate institution. These cultural differences may result in different ways of thinking about such activities. Hence, the different factor loadings.

Because the U.S. Activity factor has significant overlap with the Irish Appearance factor, it is not surprising that both of these are predictive of the non-academic and general self-concepts in the Irish sample. What is perhaps surprising is that the hiding items associated with the Irish Appearance factor (e.g., I try not to tell people my test grades) would be positively predictive of self-concept. These items in the U.S. Hiding factor predict general self-concept negatively. It could be that the activity items also loading on the Irish Appearance factor influenced the contribution to prediction, or it may be that the hiding items associated with managing appearances are positively associated with self-concept among the Irish students. Further research is needed to clarify this relationship.

When included in the regression model, age is negatively predictive of all three selfconcept subscales (academic, non-academic, and general) in the Irish sample, but not in the U.S. sample (see Tabl e 4). This means that as Irish children get older, their self-concept decreases predictably in relation to their coping behaviors, whereas this age effect does not occur in the U.S. sample. Marsh and colleagues have consistently found a decrease in self-concept with age (Marsh, 1989; Marsh \& Ayotte, 2003; Marsh, Barnes, Cairns, \& Tidman, 1984; Marsh \& Craven, 1997). These findings did not come from studies using samples of gifted students, however, which may be an explanation of the US findings of no relationship. Because they are 
unlikely to have received attention to their abilities in school (O'Reilly, 2013), the Irish gifted students may be more similar to a general population. Further research is needed to clarify the relationship of giftedness, age, social coping, and self-concept.

\section{Beliefs as Strategy}

According to Coleman and Cross's (1988) stigma of giftedness paradigm, gifted students will act to maintain social latitude in the presence of a stigmatizing condition - their giftedness. The social coping literature describes studies that attempt to identify these actions and their consequences. The actions found in this and other studies of social coping include hiding one's giftedness, sometimes through conformity, engaging in activities, using humor, and helping others. In addition to these, researchers have identified beliefs that have been considered strategies for coping with the stigma of giftedness (Swiatek, 2001). The implication is that these beliefs are consciously adopted as a protective measure, but this assumption has not been tested. Is a denial of giftedness or its impact on relationships motivated behavior? Or is it a result of the information these students have about giftedness or high academic abilities? What knowledge do these students have about the label or about academic abilities of their peers? Assessing the impact of one's differentness on peer relationships, if they indeed perceive themselves as different (Coleman \& Cross, 1988; Janos, Fung \& Robinson, 1985), requires a sophisticated analysis of a social situation about which these students may not have much information. Further research is needed to understand the explicit and implicit underpinnings of gifted students' denial of their abilities and the impact of those abilities on peer relationships.

\section{Denial of Giftedness and Self-Concept}

The perspective taken over the past 15 years of research on social coping among gifted students assumes that a denial of giftedness is a response to the stigma of giftedness (Swiatek, 
2001; Swiatek \& Dorr, 1998). As a form of impression management (Coleman \& Cross, 1988; Cross, Coleman, \& Terhaar-Yonkers, 1991), denying one's giftedness may provide protection from harassment or rejection by peers. In an effort to make oneself appear like peers, rejecting the gifted label may be adaptive. Because of its association with a negative self-concept, denial of giftedness should be challenged. A denying gifted student may be encouraged to accept her or his giftedness or questioned about the evidence of stigmatization. Is there an actual prejudice among peers against gifted students? If not, the denying gifted student may change his or her attitude with that knowledge. If so, can that prejudice be reduced?

Another explanation for the denial of giftedness is a simple lack of information. U.S. students often do not receive an explanation for their assignment to gifted programs or services. They are left to intuit the differences that have been identified. Students in this situation may deny their giftedness because they believe others are more gifted than they or that they have been lucky in their pursuits. In Ireland, few students would receive such an identification in school, and no information about their abilities would be shared. Students who deny the impact of their giftedness - or, in the case of the Irish students, their exceptional abilities - may believe that there is no impact on their acceptance by peers. Adults who attempt to protect students from a perceived stigma by encouraging students to "just be yourself," may be doing the children a disservice. Socialization includes lessons in developing an awareness of others and the effect of one's behaviors on those around them (Eisenberg, 2003; Eisenberg \& Morris, 2004). Students in the high self-concept cluster tend to disagree that there is no impact of their giftedness on peer acceptance. More research is needed to understand just what this impact is and how to help students effectively navigate their peer relationships. The findings of this study suggest that students in both countries should be helped to understand where their exceptional abilities lie on 
a continuum of abilities and what this may mean for them in relationships with peers.

Encouragement to use their abilities to help peers when possible and to engage in extracurricular activities that may be unrelated to their exceptional abilities may be helpful to gifted students' non-academic self-concept. Gifted students may need direct lessons in social skills (J. R. Cross, 2012; Webb, Gore, Amend, \& DeVries, 2007). Such skill development may be overlooked by the significant adults in a child's life, who may be focused on the child's exceptional academic abilities or who may assume advanced levels of development in all areas because of the exceptional abilities they observe.

\section{Limitations}

Cultural differences contributed to the challenges facing this study. Although the US and Irish samples included students participating in selective programs for gifted students, the Irish students, who did not bear the label gifted, received a modified survey. This limitation afforded us an opportunity for a comparative examination of social coping among these $3^{\text {rd }}-8^{\text {th }}$ grade students.

\section{Conclusion}

Young students with gifts and talents in both the US and Ireland engage in social coping behaviors or beliefs, some of which are associated with their self-concepts. To better understand the source of these behaviors and beliefs, future research is needed to explore the social experience of giftedness and how it motivates such coping behaviors or beliefs. This study identified a relationship among an acceptance of one's giftedness and a belief that giftedness does impact peer relationships and positive self-concept. Activity level, including helping one's peers, is positively associated with self-concept, even when students deny their giftedness, as we found among the Irish students. Although the causal direction is unknowable from this analysis, 
gifted students may benefit from encouragement to participate in extracurricular activities. Selfconcept may be supported by encouraging socially acceptable strategies for expressing one's exceptional abilities, such as developing an awareness of their effect on peer relationships or encouraging helping behaviors.

\section{References}

Baumeister, R. F., \& Leary, M. R. (1995). The need to belong: Desire for interpersonal attachments as a fundamental human motivation. Psychological Bulletin, 117, 497-529.

Chan, D. W. (2003). Dimensions of emotional intelligence and their relationships with social coping among gifted adolescents in Hong Kong. Journal of Youth and Adolescence, 32, 409-418.

Chan, D. W. (2004). Social coping and psychological distress among Chinese gifted students in Hong Kong. Gifted Child Quarterly, 48, 30-41.

Chan, D. W. (2005). The structure of social coping among Chinese gifted children and youths in Hong Kong. Journal for the Education of the Gifted, 29, 8-29.

Coleman, L. J. (1985). Schooling the gifted. Menlo Park, CA: Addison-Wesley.

Coleman, L. J. (2012). Lived experience, mixed messages, and stigma. In T. L. Cross \& J. R. Cross (Eds.), Handbook for counselors serving students with gifts and talents (pp. 371392). Waco, TX: Prufrock Press.

Coleman, L. J., \& Cross, T. L. (1988). Is being gifted a social handicap? Journal for the Education of the Gifted, 11, 41-56.

Coleman, L., \& Cross, T. L. (2005). Being gifted in school. Waco, TX: Prufrock Press.

Coleman, L. J., \& Sanders, M. D. (1993). Understanding the needs of gifted students: Social 
needs, social choices and masking one's giftedness. Journal of Secondary Gifted Education, 5, 22-25.

Coopersmith, S. A. (1967). The antecedents of self-esteem. San Francisco: W. H. Freeman.

Cross, J. R. (2012). Peer relations. In T. L. Cross \& J. R. Cross (Eds.), Handbook for counselors serving students with gifts and talents (pp. 409-426). Waco, TX: Prufrock Press.

Cross, T. L., Coleman, L. J., and Stewart, R. A. (1993). The social cognition of gifted adolescents: An exploration of the stigma of giftedness paradigm. Roeper Review 16, 37 40.

Cross, T. L., Coleman, L. J., and Terhaar-Yonkers, M. (1991). The social cognition of gifted adolescents in schools: Managing the stigma of giftedness. Journal for the Education of the Gifted, 15, 44-55.

Cross, T. L., \& Swiatek, M. A. (2009). Longitudinal change in social coping over one year of enrollment at a residential high school for gifted students. Gifted Child Quarterly, 53, 2533.

Eccles, J., Midgley, C , \& Adler, T. (1984). Grade-related changes in the school environment. In M. L. Maehr (Ed.), Advances in motivation and achievement (pp. 283-331). Greenwich, CT: JAI Press.

Eisenberg, N. (2003). Prosocial behavior, empathy, and sympathy. In M. H. Bornstein, L. Davidson, C. L. M. Keyes, \& K. A. Moore (Eds.), Well-being: Positive development across the life course (pp. 253-265). Mahwah, NJ: Lawrence Erlbaum.

Eisenberg, N., \& Morris, A. S. (2004). Moral cognitions and prosocial responding in adolescence. In R. M. Lerner \& L. Steinberg (Eds.), Handbook of adolescent psychology ( $2^{\text {nd }}$ ed.; pp. 155-188). Hoboken, NJ: John Wiley \& Sons. 
Exline, J. J., \& Lobel, M. (1999). The perils of outperformance: Sensitivity about being the target of a threatening upward comparison. Psychological Bulletin, 125, 307-337.

Foust, R. C., Rudasill, K. M., \& Callahan, C. M. (2006). An investigation into the gender and age differences in the social coping of academically advanced students. Journal of Advanced Academics, 18, 60-80.

Frydenberg, E., \& Lewis, R. (1991). Adolescent coping: The different ways in which boys and girls cope. Journal of Adolescence, 14, 119-133.

Gross, M. U. M. (1989). The pursuit of excellence or the search for intimacy? The forced-choice dilemma of gifted youth. Roeper Review, 11, 189-194.

Hoge, R. D., \& Renzulli, J. S. (1993). Exploring the link between giftedness and self-concept. Review of Educational Research, 63, 449-465.

Holder, M., \& Coleman, B. (2008). The contribution of temperament, popularity, and physical appearance to children's happiness. Journal of Happiness Studies, 9(2), 279-302. http://dx.doi.org/10.1007/s10902-007-9052-7

Huryn, J. S. (1986). Giftedness as deviance: A test of interaction theories. Deviant Behavior, 7, $175-186$.

James, W. (1963/1890). The principles of psychology. New York: Holt, Rinehart \& Winston. (Work originally published 1890)

Janos, P. M., Fung, H. C., \& Robinson, N. M. (1985). Self-concept, self-esteem, and peer relations among gifted children who feel "different". Gifted Child Quarterly, 29, 78-82.

Kerr, B. A., Colangelo, N., \& Gaeth, J. (1988). Gifted adolescents' attitudes toward their giftedness. Gifted Child Quarterly, 32, 245-247.

Lazarus, R. S., \& Folkman, S. (1984). Stress, appraisal, and coping. New York, NY: Springer. 
Locke, K. D. (2006). What predicts well-being: A consistent self-concept or a desirable selfconcept? Journal of Social and Clinical Psychology, 25, 228-247.

Manor-Bullock, R., Look, C., \& Dixon, D. N. (1995). Is giftedness socially stigmatizing? The impact of high achievement on social interactions. Journal for the Education of the Gifted, 18, 319- 338.

Marsh, H. W. (1989). Age and sex effects in multiple dimensions of self-concept: Preadolescence to early adulthood. Journal of Educational Psychology, 81, 417-430.

Marsh, H. W. (1990). The causal ordering of academic self-concept and academic achievement: A multiwave, longitudinal panel analysis. Journal of Educational Psychology, 82, 646656.

Marsh, H. W. (1992) Self-description questionnaire (SDQ-I): A theoretical and empirical basis for the measurement of multiple dimensions of pre-adolescent self-concept. MacArthur, New South Wales, Australia: University of Western Sydney.

Marsh, H. W. (1993). Academic self-concept: Theory measurement and research. In J. Suls (Ed.), Psychological perspectives on the self(Vol. 4, pp. 59-98). Hillsdale, NJ: Erlbaum.

Marsh, H. W., \& Ayotte, V. (2003). Do multiple dimensions of self-concept become more differentiated with age? The differential distinctiveness hypothesis. Journal of Educational Psychology, 95, 687-706.

Marsh, H. W., Barnes, J., Cairns, L., \& Tidman, M. (1984). Self Description Questionnaire: Age effects in the structure and level of self-concept for preadolescent children. Journal of Educational Psychology, 76, $940-956$.

Marsh, H. W., Byrne, B. M., \& Shavelson, R. (1988). A multifaceted academic self-concept: Its hierarchical structure and its relation to academic achievement. Journal of Educational 
Psychology, 80, 366-380.

Marsh, H. W., \& Craven, R. G. (1997). Academic self-concept: Beyond the dustbowl. In G. Phye (Ed.), Handbook of classroom assessment: Learning, achievement and adjustment (pp. 131-198). Orlando, FL: Academic Press.

Marsh, H. W., Plucker, J. A., \& Stocking, V. B. (2001). The Self-Description Questionnaire II and gifted students: Another look at Plucker, Taylor, Callahan, and Tomchin's (1997) "Mirror, mirror on the wall". Educational \& Psychological Measurement, 61(6), 976997.

Marsh, H. W., \& Shavelson, R. J. (1985). Self-concept: Its multifaceted, hierarchical structure. Educational Psychologist, 20, 107-123.

Marsh, H. W., Trautwein, U., Lüdtke, O., Köller, O., Baumer, J. (2006). Integration of multidimensional self-concept and core personality constructs: Construct validation and relations to well-being and achievement. Journal of Personality, 74, 403-456.

Marsh, H. W., \& Yeung, A. S. (1997a). The causal effects of academic self-concept on academic achievement: Structural equation models of longitudinal data. Journal of Educational Psychology, 89, 41-54.

Marsh, H. W., \& Yeung, A. (1997b). Coursework selection: Relations to academic self-concept and achievement. American Educational Research Journal, 34, 691-720.

McReynolds, P., Altrocchi, J., \& House, C. (2000). Self-pluralism: Assessment and relations to adjustment, life changes, and age. Journal of Personality, 68, 347-381.

Möller, J., Pohlmann, B., Koller, O., \& Marsh, H. W. (2009). A meta-analytic path analysis of the internal/external frame of reference model of academic achievement and academic self-concept. Review of Educational Research, 79, 1129-1167. 
O’Reilly, C. (2013). Gifted education in Ireland. Journal for the Education of the Gifted, 36, 97118. doi:10.1177/0162353212470039

O’Rourke, J., Cooper, M., \& Gray, C. (2012). Is being “smart and well behaved” a recipe for happiness in Western Australian primary schools? International Journal of Psychological Studies, 4, 139-152.

Peine, M., \& Coleman, L. (2010). The phenomenon of waiting in class. Journal for the Education of the Gifted, 34, 220-244.

Rayner, S. G. (2001). Aspects of the self as learner: Perception, concept, and esteem. In R. J. Riding \& S. G. Rayner (Eds.), Self-Perception (pp. 25-52). Westport, CT: Ablex.

Reis, S. M., Westberg, K. L., Kulikowich, J., Caillard, F., Hébert, T., Plucker, J., . . Smist, J. M. (1993). Why not let high ability students start school in January? The curriculum compacting study (Research Monograph 93106). Storrs: University of Connecticut, The National Research Center for the Gifted and Talented.

Rosenberg, M. (1979). Conceiving the self. New York, NY: BasicBooks.

Rudasill, K. M., Foust, R. C., \& Callahan, C. M. (2007). The Social Coping Questionnaire: An examination of its structure with an American sample of gifted adolescents. Journal for the Education of the Gifted, 30, 353-371.

Shavelson, R. J., Hubner, J. J., \& Stanton, G. C. (1976). Validation of construct interpretations. Review of Educational Research, 46, 407-441.

Skaalvik, E. M., and Hagtvet, K. A. (1990). Academic achievement and self-concept: An analysis of causal predominance in a developmental perspective. Journal of Personality and Social Psychology, 58, 292-307.

Skaalvik, E. M., \& Skaalvik, S. (2009). Self-concept and self-efficacy in mathematics: Relation 
with mathematics motivation and achievement. Journal of Education Research, 3, 255277.

Swiatek, M. A. (1995). An empirical investigation of the social coping strategies used by gifted adolescents. Gifted Child Quarterly, 39, 154-161.

Swiatek, M. A. (2001). Social coping among gifted high school students and its relationship to self-concept. Journal of Youth and Adolescence, 30, 19-39.

Swiatek, M. A. (2002). Social coping among gifted elementary school students. Journal for the Education of the Gifted, 26, 65-86.

Swiatek, M. A., \& Cross, T. L. (2007). Construct validity of the Social Coping Questionnaire. Journal for the Education of the Gifted, 30, 427-449.

Swiatek, M. A., \& Dorr, R. M. (1998). Revision of the Social Coping Questionnaire: Replication and extension of previous findings. Journal of Secondary Gifted Education, 10, 252-259.

Tannenbaum, A. (1983). Gifted children: Psychological and educational perspectives. New York, NY: John Wiley.

Tomchin, E. M., \& Callahan, C. M. (1996). Coping and self-concept. Journal of Secondary Gifted Education, 8, 16-27.

Webb, J. T., Gore, J. L., Amend, E. R., \& DeVries, A. R. (2007). A parent's guide to gifted children. Scottsdale, AZ: Great Potential Press. 
Table 1

Social Coping Factor Loadings for U.S. Sample

\begin{tabular}{|c|c|c|}
\hline $\begin{array}{l}\text { Factor } \\
\text { Description }\end{array}$ & Item & $\begin{array}{l}\text { Factor } \\
\text { Loadings }\end{array}$ \\
\hline \multirow[t]{3}{*}{ Conformity } & I try to act very much like other students act & .784 \\
\hline & I try to look very similar to other students & 620 \\
\hline & I would fit in better at school if I were not gifted & .343 \\
\hline \multirow[t]{3}{*}{ Humor } & I tell a lot of jokes in school & .811 \\
\hline & I'm good at making people laugh & .734 \\
\hline & People think of me as a "class clown" & .707 \\
\hline \multirow{6}{*}{$\begin{array}{l}\text { Deny } \\
\text { Giftedness }\end{array}$} & I don't think that I am gifted & .762 \\
\hline & I am not gifted; I am just lucky in school & .731 \\
\hline & There are many people who are more gifted than I am & .411 \\
\hline & People think that I am gifted, but they are mistaken & .501 \\
\hline & $\begin{array}{l}\text { As I get older and academic work gets more difficult, people } \\
\text { will stop seeing me as gifted }\end{array}$ & .522 \\
\hline & Most of the successes I experience are due to luck & .342 \\
\hline \multirow[t]{7}{*}{ Activity } & People come to me for help with their homework &. .500 \\
\hline & I try to use what I know to help other students & .594 \\
\hline & I keep myself quite busy most of the time & .565 \\
\hline & $\begin{array}{l}\text { I find friends who have interests similar to mine by getting } \\
\text { involved in extracurricular activities }\end{array}$ & .554 \\
\hline & $\begin{array}{l}\text { I explain course material to other students when they don't } \\
\text { understand it }\end{array}$ & .526 \\
\hline & I spend quite a bit of time on extracurricular activities & .484 \\
\hline & $\begin{array}{l}\text { Because of all my activities, I don't have time to worry about } \\
\text { my popularity }\end{array}$ & .381 \\
\hline \multirow[t]{4}{*}{ Deny Impact } & $\begin{array}{l}\text { If I were not gifted, other kids in my school would not like } \\
\text { me any more or less than they do now }\end{array}$ & .664 \\
\hline & Being gifted does not hurt my popularity & .433 \\
\hline & Other students do not like me any less because I am gifted & .546 \\
\hline & I try not to be too successful at the things I do & .856 \\
\hline \multirow[t]{4}{*}{ Unconcerned } & I don't worry about whether or not I am popular & .624 \\
\hline & Being popular is not important in the long run & .452 \\
\hline & It doesn't matter what other people think about me & .539 \\
\hline & I prefer doing things alone to doing things with other kids & .372 \\
\hline \multirow[t]{2}{*}{ Hiding } & I don't tell people that I am gifted & .497 \\
\hline & I try not to tell people my test grades & .308 \\
\hline
\end{tabular}


Table 2

Social Coping factor loadings for Irish Sample

\begin{tabular}{|c|c|c|}
\hline $\begin{array}{l}\text { Factor } \\
\text { Description }\end{array}$ & Item & $\begin{array}{l}\text { Factor } \\
\text { Loadings }\end{array}$ \\
\hline \multirow{7}{*}{$\begin{array}{l}\text { Deny } \\
\text { Giftedness }\end{array}$} & I don't think that I have high academic abilities & .831 \\
\hline & I don't have high academic abilities; I am just lucky in school & .728 \\
\hline & $\begin{array}{l}\text { People think that I have high academic abilities, but they are } \\
\text { mistaken }\end{array}$ & .766 \\
\hline & $\begin{array}{l}\text { As I get older and academic work gets more difficult, people } \\
\text { will stop seeing me as having high academic abilities }\end{array}$ & .642 \\
\hline & $\begin{array}{l}\text { There are many people who have higher academic abilities } \\
\text { than I do }\end{array}$ & .677 \\
\hline & Most of the successes I experience are due to luck & .402 \\
\hline & I don't tell people that I have high academic abilities & .420 \\
\hline \multirow[t]{4}{*}{ Humor } & I tell a lot of jokes in school & .837 \\
\hline & I am good at making people laugh & 626 \\
\hline & People think of me as a "class clown" & .584 \\
\hline & Most people see me as quite serious & .373 \\
\hline \multirow[t]{4}{*}{ Appearance } & I try not to tell people my test grades & .735 \\
\hline & I try to hide my high academic abilities from other students & .444 \\
\hline & I spend quite a bit of my time on extracurricular activities & .490 \\
\hline & $\begin{array}{l}\text { I find friends who have interests similar to mine by getting } \\
\text { involved in extracurricular activities }\end{array}$ & .389 \\
\hline \multirow[t]{3}{*}{ Unconcerned } & I don't worry about whether or not I am popular & 698 \\
\hline & Being popular is not important in the long run & 677 \\
\hline & $\begin{array}{l}\text { Because of all my activities, I don't have time to worry about } \\
\text { my popularity }\end{array}$ & .544 \\
\hline \multirow[t]{3}{*}{ Helping } & $\begin{array}{l}\text { I explain course material to other students when they don't } \\
\text { understand it }\end{array}$ & .791 \\
\hline & I try to use what I know to help other students & .474 \\
\hline & People come to me for help with their homework & .561 \\
\hline \multirow[t]{3}{*}{ Deny Impact } & Having high academic abilities does not hurt my popularity & .714 \\
\hline & $\begin{array}{l}\text { Other students do not like me any less because I have high } \\
\text { academic abilities }\end{array}$ & .591 \\
\hline & I prefer doing things alone to doing things with other kids & .448 \\
\hline \multirow[t]{5}{*}{ Conformity } & I would fit in better at school if I were not gifted & .726 \\
\hline & I try to look very similar to other students & .657 \\
\hline & I try to act very much like other students act & .571 \\
\hline & I try not to be too successful at the things I do & .556 \\
\hline & $\begin{array}{l}\text { I try to get involved in sports so that people don't think of me } \\
\text { as a "geek" }\end{array}$ & .538 \\
\hline
\end{tabular}


Table 3

Cross-Cultural Self-Concept Comparison

\begin{tabular}{lcccc}
\hline & \multicolumn{2}{c}{ US $(N=134)$} & \multicolumn{2}{c}{ Irish $(N=115)$} \\
\hline & $M(S D)$ & $\alpha$ & $M(S D)$ & $\alpha$ \\
\hline Physical Appearance & $3.90(.66)$ & .81 & $3.23(.61)$ & .75 \\
Physical Ability & $3.90(.73)$ & .82 & $3.18(.85)$ & .82 \\
Parent Relations & $4.25(.61)$ & .80 & $3.86(.69)$ & .85 \\
Peer Relations & $3.90(.68)$ & .87 & $3.42(.65)$ & .76 \\
General School & $4.05(.63)$ & .76 & $3.29(.64)$ & .80 \\
Reading & $4.33(.71)$ & .84 & $3.88(.48)$ & .75 \\
Mathematics & $4.03(.90)$ & .90 & $3.63(.63)$ & .77 \\
General Self & $4.22(.58)$ & .74 & $3.46(.47)$ & .68 \\
\hline Academic & $4.14(.59)$ & & $3.60(.46)$ & \\
Nonacademic & $3.99(.47)$ & & $3.42(.54)$ & \\
\hline Note: All are & & & & \\
\hline
\end{tabular}

Note: All are different at $p<.001$ 
Table 4

Multiple Regression Analysis Summaries for Variables Predicting Students' Academic, Nonacademic, and General Self-Concept

\begin{tabular}{|c|c|c|c|c|c|c|c|c|}
\hline & & $\mathrm{US}(N=134)$ & & & & Irish & $V=115$ & \\
\hline $\begin{array}{l}\text { Dependent } \\
\text { Variable }\end{array}$ & $\begin{array}{l}\text { Predictor } \\
\text { variable }\end{array}$ & $B$ & $S E B$ & $\beta$ & Predictor variable & $B$ & $S E B$ & $\beta$ \\
\hline \multirow[t]{4}{*}{$\begin{array}{l}\text { Academic } \\
\text { Self-concept }\end{array}$} & $\begin{array}{l}\text { Deny } \\
\text { Giftedness }\end{array}$ & -.213 & .065 & -.255 & Deny Giftedness & -.227 & .080 & -.254 \\
\hline & Activity & .259 & .052 & .383 & $\begin{array}{l}\text { Helping } \\
\text { Age }\end{array}$ & $\begin{array}{l}.266 \\
-.111\end{array}$ & $\begin{array}{l}.069 \\
.042\end{array}$ & $\begin{array}{l}.317 \\
-.222\end{array}$ \\
\hline & $R^{2}=.214$ & & & & $R^{2}=.249$ & & & \\
\hline & $F=17.890^{*}$ & & & & $F=12.243^{*}$ & & & \\
\hline \multirow{3}{*}{$\begin{array}{l}\text { Nonacademic } \\
\text { Self-concept }\end{array}$} & Humor & .088 & .027 & .251 & Humor & .279 & .081 & .268 \\
\hline & $\begin{array}{l}\text { Deny } \\
\text { Giftedness }\end{array}$ & -.182 & .051 & -.276 & Deny Giftedness & -.293 & .080 & -.287 \\
\hline & $\begin{array}{l}R^{2}=.236 \\
F=13.421 *\end{array}$ & .173 & .041 & .323 & $\begin{array}{l}\text { Appearance } \\
\text { Deny Impact } \\
\text { Age } \\
R^{2}=.380 \\
F=13.343^{*}\end{array}$ & $\begin{array}{l}.210 \\
-.186 \\
-.083\end{array}$ & $\begin{array}{l}.074 \\
.064 \\
.044\end{array}$ & $\begin{array}{l}.218 \\
-.225 \\
-.154\end{array}$ \\
\hline \multirow[t]{3}{*}{$\begin{array}{l}\text { General Self- } \\
\text { concept }\end{array}$} & Humor & .091 & .033 & .210 & Deny Giftedness & -.488 & .075 & -.522 \\
\hline & $\begin{array}{l}\text { Deny } \\
\text { Giftedness }\end{array}$ & -.276 & .062 & -.336 & Appearance & .163 & .070 & .185 \\
\hline & $\begin{array}{l}\text { Activity } \\
\text { Hiding } \\
R^{2}=.266 \\
F=11.688^{*}\end{array}$ & $\begin{array}{l}.211 \\
-.062\end{array}$ & $\begin{array}{l}.051 \\
.029\end{array}$ & $\begin{array}{l}.317 \\
-.159\end{array}$ & $\begin{array}{l}\text { Age } \\
R^{2}=.332 \\
F=18.394 *\end{array}$ & -.036 & .040 & -.073 \\
\hline
\end{tabular}


$* p<.05$ 
Table 5

Self-Concept Cluster Demographics

\begin{tabular}{rcccccc}
\hline & & US $(N=134)$ & & \multicolumn{3}{c}{ Irish $(N=115)$} \\
\hline Cluster & Male/ & Elementary/ & & Male/ & Elementary/ & \\
High & $23 / 14$ & Secondary & Total & Female & Secondary & Total \\
Medium & $42 / 30$ & $37 / 35$ & 33 & $24 / 14$ & $21 / 21$ & 42 \\
Low & $15 / 7$ & $9 / 14$ & 23 & $33 / 25$ & $15 / 44$ & 59 \\
\hline
\end{tabular}

Note: Totals reflect missing data. Elementary = Grades 3-5; Secondary = Grades 6-8 
Table 6

Mean scores by self-concept clusters

\begin{tabular}{|c|c|c|c|c|c|c|c|}
\hline & \multicolumn{3}{|c|}{ Self-Concept Cluster - U.S. sample } & & \multicolumn{3}{|c|}{ Self-Concept Cluster - Irish sample } \\
\hline & High & Medium & Low & & High & Medium & Low \\
\hline & $(n=38)$ & $(n=73)$ & $(n=23)$ & & $(n=42)$ & $(n=59)$ & $(n=14)$ \\
\hline & $\mathrm{M}(\mathrm{SD})$ & $\mathrm{M}(\mathrm{SD})$ & $\mathrm{M}(\mathrm{SD})$ & & $\mathrm{M}(\mathrm{SD})$ & $\mathrm{M}(\mathrm{SD})$ & $\mathrm{M}(\mathrm{SD})$ \\
\hline Academic Self-Concept & $4.64(.27)$ & $4.09(.45)$ & $3.46(.61)$ & Academic Self-Concept & $3.89(.26)$ & $3.56(.40)$ & $2.87(.34)$ \\
\hline Non-Academic Self-Concept & $4.49(.17)$ & $3.92(.32)$ & $3.39(.33)$ & Non-Academic Self-Concept & $3.92(.27)$ & $3.28(.34)$ & $2.54(.36)$ \\
\hline General Self-Concept & $4.81(.21)$ & $4.20(.32)$ & $3.31(.41)$ & General Self-Concept & $3.84(.32)$ & $3.35(.32)$ & $2.80(.44)$ \\
\hline Deny Giftedness & $1.91(.50)$ & $1.97(.60)$ & $2.59(1.03)$ & Deny Giftedness & $2.3(.77)$ & $2.68(1.04)$ & $3.31(1.13)$ \\
\hline Deny Impact & $1.31(.43)$ & $1.48(.56)$ & $1.64(.32)$ & Deny impact & $2.19(1.15)$ & 3.03 (1.20) & 3.27 (1.16) \\
\hline Unconcerned & $3.44(.80)$ & $3.76(.96)$ & $3.52(1.13)$ & Unconcerned & $3.89(1.22)$ & $3.84(1.25)$ & $2.99(1.12)$ \\
\hline Hiding & $3.51(1.63)$ & 3.44 (1.57) & $3.91(.93)$ & Appearance & $3.64(1.02)$ & $3.48(1.05)$ & $2.62(.95)$ \\
\hline Activity & $4.75(.69)$ & $4.22(.86)$ & $3.85(.90)$ & Helping & $4.47(1.03)$ & 3.97 (1.16) & $3.6(1.08)$ \\
\hline
\end{tabular}




\begin{tabular}{|c|c|c|c|c|c|c|c|}
\hline Conformity & $2.90(1.54)$ & $2.37(1.32)$ & $2.78(1.20)$ & Conformity & $1.89(.80)$ & $2.73(1.05)$ & $2.45(.71)$ \\
\hline Humor & 4.04 (1.17) & $3.40(1.34)$ & $3.58(1.44)$ & Humor & $3.74(.94)$ & $3.21(.93)$ & $2.66(.90)$ \\
\hline
\end{tabular}


Figure 1. Significantly different social coping strategies among self-concept clusters in the U.S. sample.

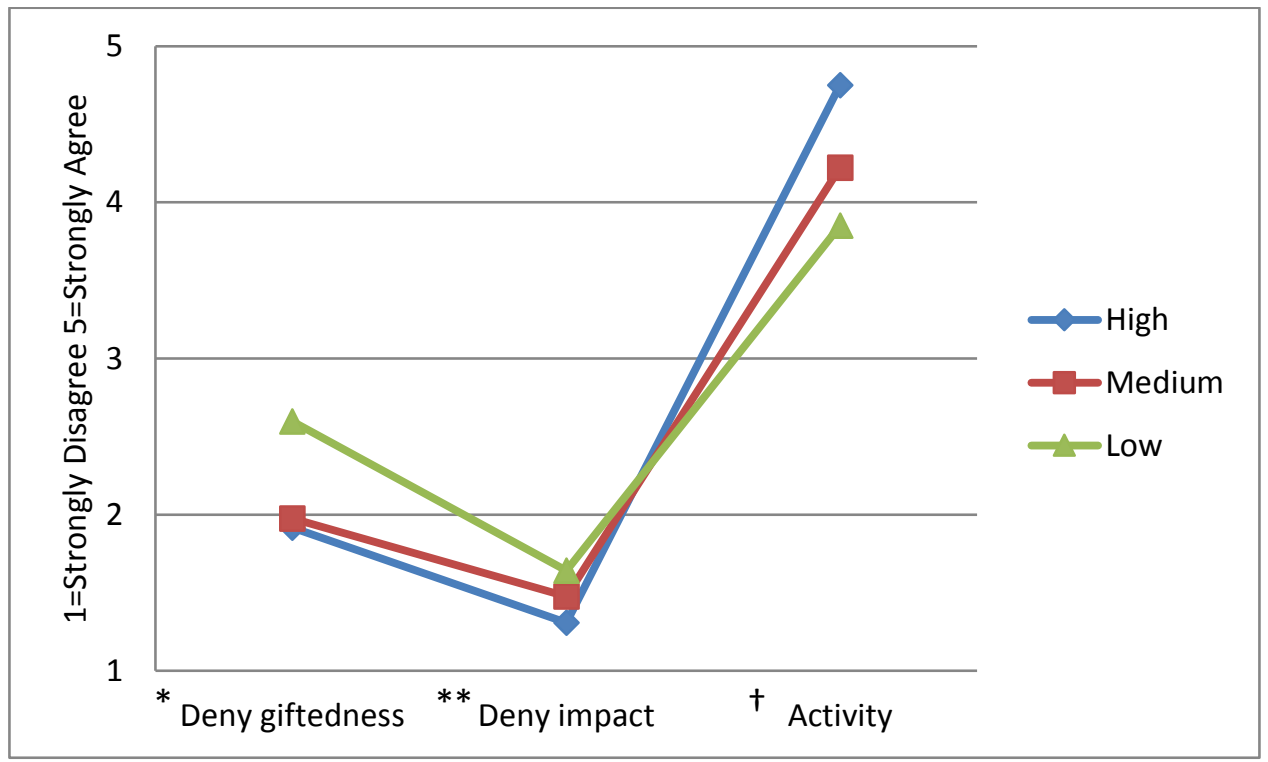

Note: * Low cluster is different from High and Medium $(p<.05)$

** Low cluster is different from High $(p<.05)$

$\dagger$ High cluster is different from Medium and Low $(p<.05)$ 
Figure 2. Significantly different social coping strategies among self-concept clusters in the Irish sample.

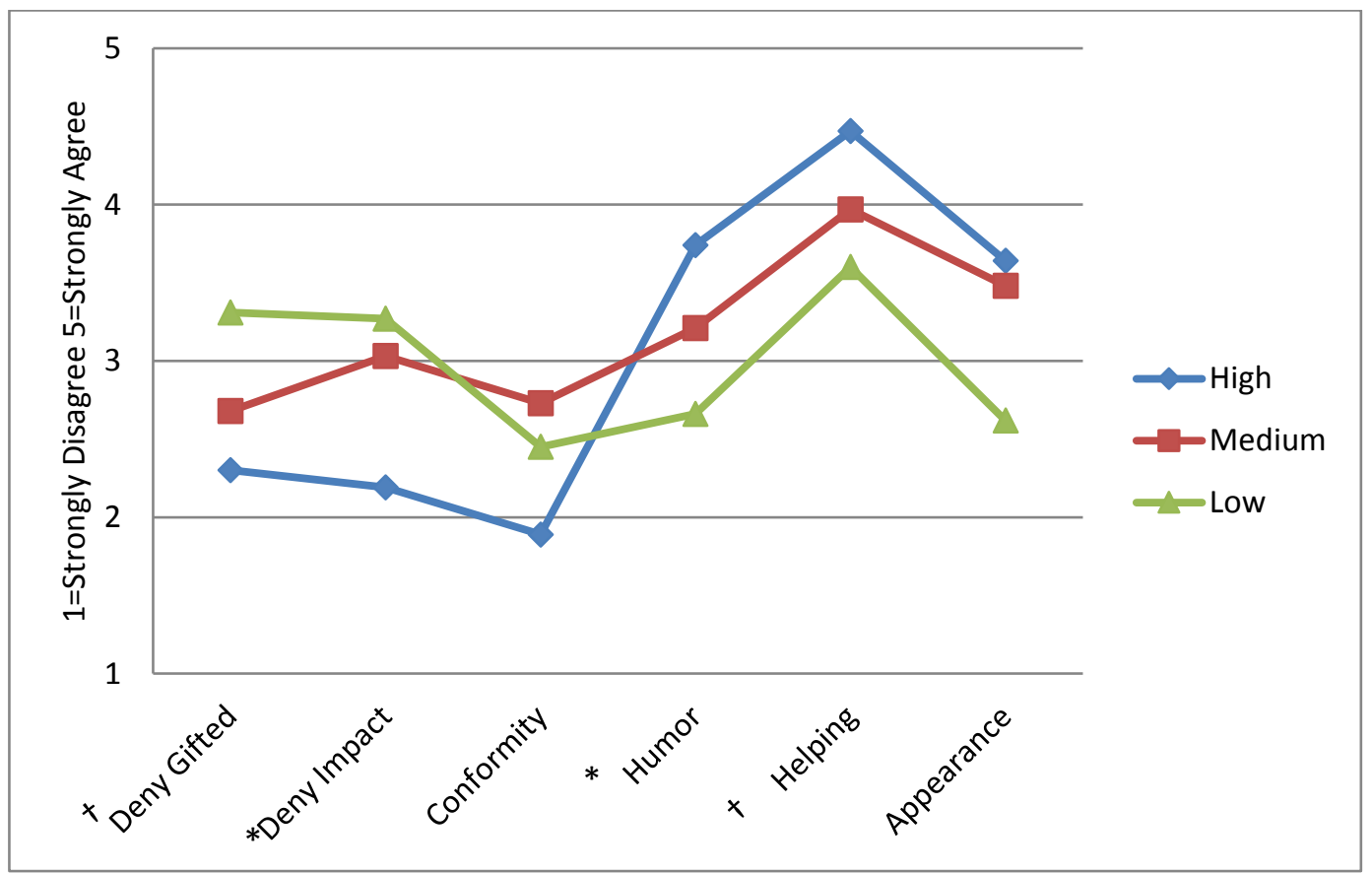

Note:

*High cluster is different from Medium and Low $(p<.05)$

$\dagger$ Low cluster is different from High $(p<.05)$ 